\title{
Carriage of Shiga toxin phage profoundly affects Escherichia coli gene expression and carbon source utilization
}

Petya Berger ${ }^{1 *} \mathbb{D}$, Ivan U. Kouzel ${ }^{1,2}$, Michael Berger ${ }^{1}$, Nadja Haarmann', Ulrich Dobrindt ${ }^{1}$, Gerald B. Koudelka ${ }^{3}$ and Alexander Mellmann ${ }^{1}$

\begin{abstract}
Background: Enterohemorrhagic Escherichia coli (E. coli) are intestinal pathogenic bacteria that cause life-threatening disease in humans. Their cardinal virulence factor is Shiga toxin (Stx), which is encoded on lambdoid phages integrated in the chromosome. Stx phages can infect and lysogenize susceptible bacteria, thus either increasing the virulence of already pathogenic bacterial hosts or transforming commensal strains into potential pathogens. There is increasing evidence that Stx phage-encoded factors adaptively regulate bacterial host gene expression. Here, we investigated the effects of Stx phage carriage in E. coli K-12 strain MG1655. We compared the transcriptome and phenotype of naive MG1655 and two lysogens carrying closely related Stx2a phages: $\varphi$ O104 from the exceptionally pathogenic 2011 E. coli O104:H4 outbreak strain and $\varphi$ PA8 from an E. coli O157:H7 isolate.
\end{abstract}

Results: Analysis of quantitative RNA sequencing results showed that, in comparison to naive MG1655, genes involved in mixed acid fermentation were upregulated, while genes encoding NADH dehydrogenase I, TCA cycle enzymes and proteins involved in the transport and assimilation of carbon sources were downregulated in MG1655:: $\varphi$ O104 and MG1655:" $\varphi$ PA8. The majority of the changes in gene expression were found associated with the corresponding phenotypes. Notably, the Stx2a phage lysogens displayed moderate to severe growth defects in minimal medium supplemented with single carbon sources, e.g. galactose, ribose, L-lactate. In addition, in phenotype microarray assays, the Stx2a phage lysogens were characterized by a significant decrease in the cell respiration with gluconeogenic substrates such as amino acids, nucleosides, carboxylic and dicarboxylic acids. In contrast, MG1655:"9O104 and MG1655:: QPA8 displayed enhanced respiration with several sugar components of the intestinal mucus, e.g. arabinose, fucose, Nacetyl-D-glucosamine. We also found that prophage-encoded factors distinct from $\mathrm{Cl}$ and $\mathrm{Cro}$ were responsible for the carbon utilization phenotypes of the Stx2a phage lysogens.

Conclusions: Our study reveals a profound impact of the Stx phage carriage on E. coli carbon source utilization. The Stx2a prophage appears to reprogram the carbon metabolism of its bacterial host by turning down aerobic metabolism in favour of mixed acid fermentation.

Keywords: Stx2a phage, E. coli O104:H4, E. coli O157:H7, E. coli K-12 MG1655, RNA-seq, Biolog phenotype microarrays, Carbon source utilization, Carbon metabolism

\footnotetext{
* Correspondence: petya.berger@ukmuenster.de

${ }^{1}$ Institute of Hygiene, University of Münster, Münster, Germany

Full list of author information is available at the end of the article
}

(c) The Author(s). 2019 Open Access This article is distributed under the terms of the Creative Commons Attribution 4.0 International License (http://creativecommons.org/licenses/by/4.0/), which permits unrestricted use, distribution, and reproduction in any medium, provided you give appropriate credit to the original author(s) and the source, provide a link to the Creative Commons license, and indicate if changes were made. The Creative Commons Public Domain Dedication waiver (http://creativecommons.org/publicdomain/zero/1.0/) applies to the data made available in this article, unless otherwise stated. 


\section{Background}

Enterohemorrhagic E. coli (EHEC) are intestinal pathogenic bacteria, which cause diarrhea, hemorrhagic colitis (HC, bloody diarrhea) and the potentially fatal hemolytic uremic syndrome (HUS). HUS is characterized by the triad of hemolytic anemia, thrombocytopenia and acute kidney injury [1]. Due to its ability to cause HUS, EHEC is the most frequent cause of renal failure in children [2].The majority of EHEC-associated HC and HUS have been attributed to the E. coli serotype O157:H7, although non-O157 serotypes are increasingly recognized as being clinically important [1, 3-5].

The hallmark of an EHEC infection is the production of Shiga toxins (Stxs). These toxins are $\mathrm{AB}_{5}$ toxins that irreversibly inhibit host cell protein synthesis and lead to cell death [6]. There are two immunologically distinct Stx types, Stx1 and Stx2, which are further divided into the subtypes Stx1a,c,d and Stx2a-i [7-9], with Stx2a being the one most often associated with severe illness and the development of HUS [10]. Shiga toxins are encoded by prophages that are resident in EHEC and all EHEC strains harbor at least one Stx-encoding bacteriophage. The Stxencoding phages are lysogenic converting $\lambda$-like phages. Stx phages are very sequence heterogeneous, however their overall genome organization, gene regulatory patterns and lifecycle are similar to those of non-Stxencoding $\lambda$-like bacteriophages. Upon infecting a bacterial host, a lambdoid phage chooses between two developmental fates. The phage can grow lytically, thereby killing the host. Alternatively, in lysogenic growth the phage chromosome inserts into the host genome where, under the control of the DNA binding phage CI repressor, the prophage genome lies essentially dormant. Upon activation of the SOS response, a RecA-mediated cleavage of the $\mathrm{CI}$ repressor causes its dissociation from the DNA and thus triggers lytic growth. Induction/lytic phage growth is essential to EHEC pathogenesis because high level Stx production and its subsequent release only occurs during phage lytic growth [11-16].

Stx phages are highly mobile elements that mediate the horizontal gene transfer of stx genes and therefore contribute to the emergence of new pathotypes [17]. E. coli O104: H4, which caused in 2011 a massive EHEC outbreak in Germany shares highest genome sequence similarity with enteroaggregative E. coli (EAEC) and does not carry the locus of enterocyte effacement (LEE) pathogenicity island characteristic of typical EHEC isolates [18]. This led to the hypothesis that the 2011 outbreak strain has originated via Stx2a phage acquisition by an EAEC ancestor [19, 20]. Similarly, the EHEC strain E. coli O157:H7 is believed to have evolved from enteropathogenic E. coli through a series of horizontal gene transfer events including the acquisition of Stx1a- and/or Stx2a-encoding phages [21, 22]. Stx2 phages are able to infect and lysogenize both pathogenic and nonpathogenic enteric E. coli isolates in vitro, even if the hosts already possessed a Stx phage. These new lysogens can produce infectious phage particles [23]. Moreover, successful in vivo transduction of susceptible bacteria with both Stx1 and Stx2 phage derivatives has been reported $[24,25]$ and newly created lysogens of commensal $E$. coli can produce high levels of Stx2 [26, 27]. In a mouse model infected with E. coli O157:H7, Stx is more often detected in the feces of mice co-colonized with Stx phage-sensitive than with phage-resistant $E$. coli. This finding suggests that the commensal E. coli can function as surrogate hosts for Stx phage, leading to increased Stx production [28]. Thus Stx phage-susceptible commensal bacteria apparently can substantially enhance the severity of an EHEC infection.

There is increasing evidence that Stx prophage-encoded factors can modify host gene expression and thereby its phenotype. For example, microarray analysis has revealed that the Stx2a phage $\phi M i n 27$ lysogeny in E. coli K-12 strain MG1655 (MG1655) leads to the differential expression of more than 150 bacterial host genes and enhances its acid resistance and motility [29]. Similarly, transcriptomic studies applying RNA sequencing (RNA-seq) has revealed a positive effect of the Stx2a phage $\phi 24_{B}$ carriage on the expression of acid resistance genes in the E. coli $\mathrm{K}-12$ strain MC1061. This effect is mediated by the phage-encoded regulator CII [30]. Moreover, CII also apparently represses expression of elements of the LEE-encoded type III secretion system, which is crucial for EHEC virulence [31]. Also, the phage encoded anti-repressor Cro, which mediates the switch to the phage lytic cycle, activates LEE gene expression in EHEC 8624. In addition, Cro apparently affects the expression of nearly 900 genes in this strain [32].

Here, we investigated the effects of the Stx phage carriage on host gene expression and phenotype. For this work we examined the effects of two different Stx2a prophages on the commensal strain MG1655. The Stx2aencoding phages were derived from the exceptionally pathogenic 2011 E. coli O104:H4 outbreak strain and the E. coli O157:H7 strain PA8. Despite being found in two different EHEC serotypes, these two phages have a high degree of sequence similarity [33]. Naive MG1655 and the Stx2a phage converted MG1655::\$O104 and MG1655:: фPA8 were subjected to quantitative RNA-seq analysis and phenotype analysis including microarrays. We found that the prophages had a profound impact on MG1655 host gene expression, which was in turn resulting in stable, dramatic changes in the carbon source utilization.

\section{Results}

Transcriptome analysis of naive MG1655 and the Stx2a

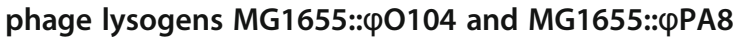

In order to analyze the influence of Stx phage carriage on host cell transcription, we performed strand specific RNA-seq with total RNA isolated from exponential 
phase naive MG1655 and the Stx2a phage lysogens MG1655::\$O104 and MG1655::\$PA8 grown under standard laboratory conditions (see Methods). On average, 14 million reads (range, 10-19 million reads) were obtained per library and more than $94 \%$ of the reads in each dataset were mapped to the respective reference genomes (Additional file 3: Table S1). Principal component analysis based on the gene expression data quantified with DESeq2 showed little variation between the biological triplicates within a strain; however there was a clear difference in between the analyzed strains (Additional file 3: Figure S1). The DESeq2 analysis further revealed that both Stx2a phage lysogens displayed multiple examples of differential gene expression in comparison to the naive MG1655 (Additional file 1 and Additional file 2). Using an adjusted $p$-value of $<0.1$ and a cut-off of 1.5 -fold difference in the expression, we found that a total of 63 genes were significantly upregulated and 69 genes were downregulated in MG1655:: $\phi O 104$. Similarly, we found 94 upregulated and 72 downregulated genes in MG1655::\$PA8 (Additional file 3: Tables S2 and S3). Importantly, we found that there was a substantial overlap of the genes that were differentially expressed in MG1655::\$O104 and MG1655::\$PA8 in comparison to naive MG1655. Our analysis indicated that $51 \%$ of the up- and $60 \%$ of the downregulated genes were shared between the lysogens (Fig. 1). In addition, $40-79 \%$ of the lysogen-specific genes were accordingly up- or downregulated in the other strain, however below one of the thresholds applied in our analysis (Additional file 1, Additional file 2 and Additional file 3: Tables S2 and S3). This observation was in agreement with the high sequence similarities between $\phi \mathrm{O} 104$ and $\phi \mathrm{PA} 8$ (85\% query coverage, 98\% identity; Additional file 3: Figure S2).

\section{Overview of the genes found upregulated in the Stx2a phage lysogens in comparison to naive MG1655}

Further analysis using the STRING database of proteinprotein interactions [34] revealed that, among others, sulfur-related genes, as well as genes involved in the SOS response, motility and chemotaxis were upregulated in the Stx2a phage lysogens in comparison to naive MG1655 (Additional file 3: Figure S3). Several genes, which were previously described to be responsive to sulfur availability [35], i.e. yeeE encoding an inner membrane protein, yeeD coding for a putative sulfur transferase and $y d j N$ encoding a cystine/cysteine/sulfocysteine: cation symporter were among the most strongly upregulated genes (6-20 fold) in both lysogens. In addition, the genes involved in the sulfur metabolism cysD, cysJ, cysK and cysPUW were significantly upregulated in MG1655::\$PA8, whereas in MG1655::\$O104 these genes were also detected upregulated but below the padj $<0.1$ applied in our analysis (Additional file 1, Additional file 2 and Additional file 3: Table S2).

The most abundant class of upregulated genes in both

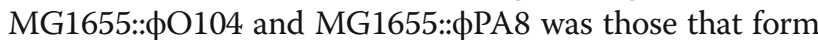
the SOS response-regulon. These genes included $r e c N$, which codes for the DNA repair protein $\operatorname{RecN}, \operatorname{rec} A$, which codes for the DNA recombination/repair protein RecA, and $u m u D C$, encoding the DNA polymerase V subunits, among others (Additional file 3: Figure S3). A detailed investigation into the SOS response-related upregulated genes detected in the Stx2a phage lysogens and their biological relevance will be presented in a separate publication (manuscript in preparation).

In addition, genes involved in motility and chemotaxis were found upregulated in both lysogens, i.e. $f l i C$ coding for flagellin, cheW and tar coding for the chemotaxis proteins CheW and Tar, respectively (Additional file 3: Figure S3). It has been previously reported that MG1655 lysogenized with the Stx2a phage $\phi$ Min27 displays elevated levels of flagellar gene transcripts and has enhanced swimming motility [29]. Similarly, we found here that MG1655:: $\phi O 104$ expressed 1.8 fold higher levels FliC and displayed a significantly increased swimming motility compared to parental naive MG1655 strain (Additional file 3: Figure S4).
Upregulated genes
in comparison to MG1655

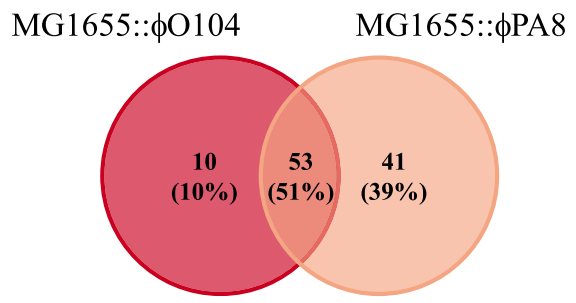

Downregulated genes

in comparison to MG1655

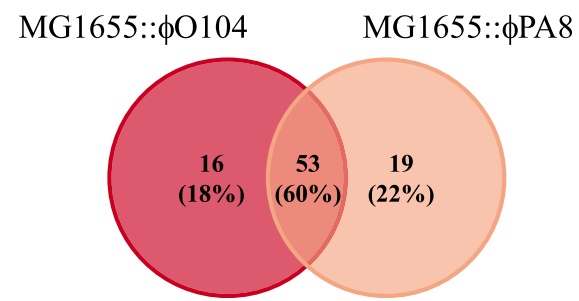

Fig. 1 Overlap of genes found to be differentially expressed in the Stx2a phage lysogens in comparison to naive MG1655. The Venn diagram shows the

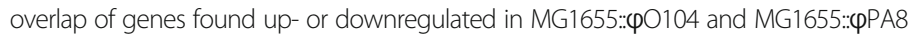


Several metabolic genes were also found upregulated in both Stx2a phage lysogens. These included the genes involved in mixed acid fermentation ack $A$ encoding the acetate kinase, ldhA coding for the D-lactate dehydrogenase and aceE coding for the pyruvate dehydrogenase complex E1 component (also functioning in linking glycolysis to the TCA cycle), as well as $n d h$ coding for the NADH dehydrogenase II.

\section{Overview of the genes found downregulated in the Stx2a} phage lysogens in comparison to naive MG1655

Interestingly, our STRING analysis revealed that the majority of the downregulated genes in the Stx2a phage lysogens were involved in carbon source transport and metabolism (Fig. 2 and Additional file 3: Figure S5). Both MG1655:: $\phi \mathrm{O} 104$ and MG1655:: $\phi$ PA8 were characterized by reduced expression of genes involved in the assimilation of: (i) galactose, e.g. $m g l B A C$ operon coding for subunits of the $\mathrm{D}$-galactose $\mathrm{ABC}$ transporter (transports also glucose) and galETKM operon encoding enzymes involved in the galactose degradation I (Leloir) pathway; (ii) D-serine, e.g. $d s d X A$ operon coding for the $\mathrm{D}$-serine transporter and ammonialyase; (iii) sialic acid, e.g. nanS encoding the $\mathrm{N}$-acetyl-9-Oacetylneuraminate esterase and the sialic acid catabolic operon $n a n A T E K-y h c H$; (iv) L-lactate, i.e. the IldPRD operon involved in L-lactate transport and degradation; (v) maltose, i.e. malK-lamB-malM operon encoding the maltose outer membrane channel and phage lambda receptor protein LamB and the malEFG operon encoding subunits of the maltose $\mathrm{ABC}$ transporter (transports also glucose); and (vi) sorbitol, i.e. srlD coding for the sorbitol-6-phosphate 2dehydrogenase and $\operatorname{srlB}$ for component of the sorbitolspecific PTS enzyme IIA. In addition, genes involved in the utilization of (vii) glycerol, e.g. $g l p Q$ coding for the

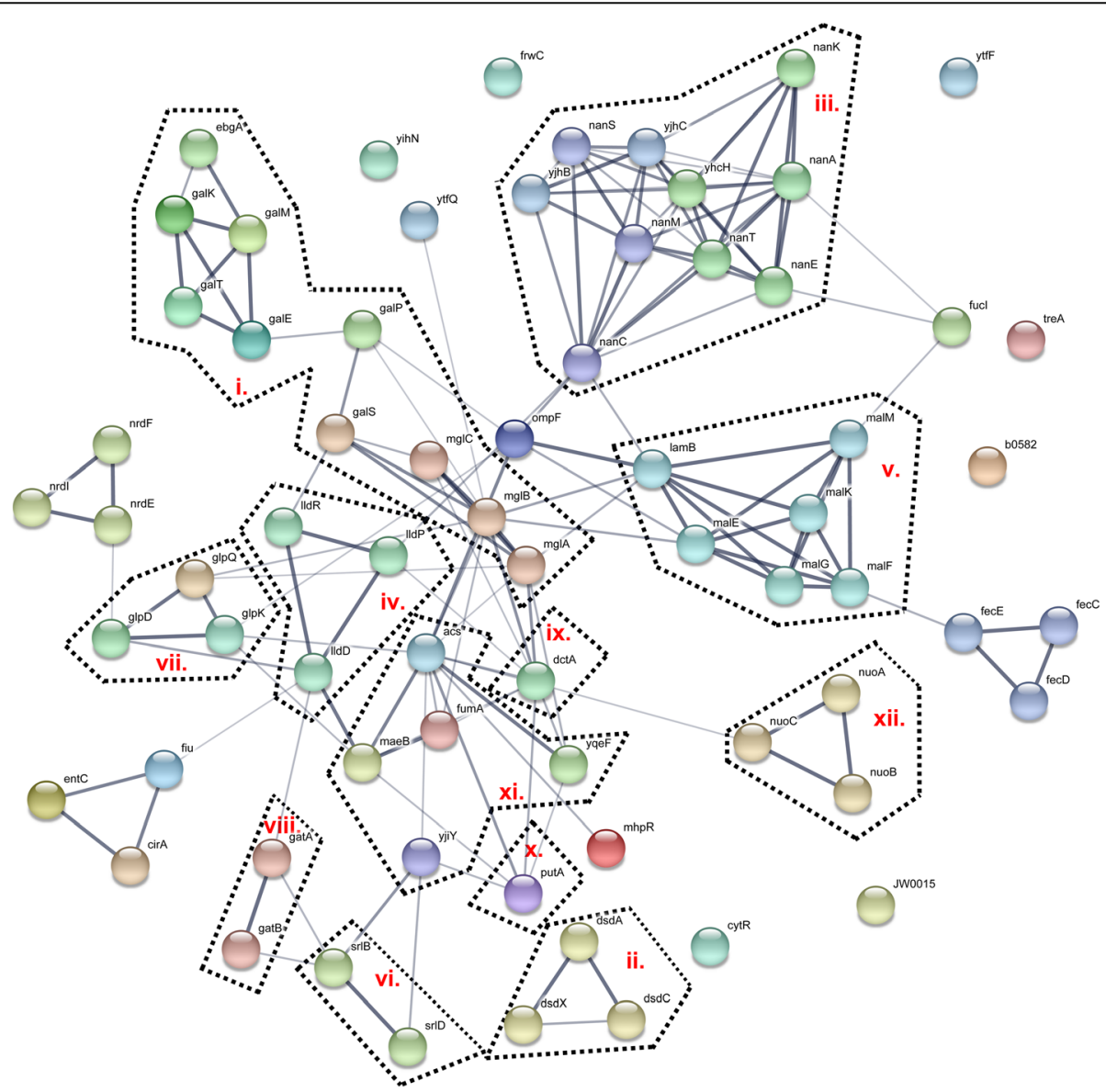

Fig. 2 Interaction network of the genes found downregulated in MG1655: comparison to naive MG1655 was analyzed using the STRING database of protein-protein interactions. The network summarizes the predicted associations for the proteins encoded by the upregulates genes detected in our analysis. The network nodes are the proteins and the edges represent the predicted functional associations. The thickness of the line indicates the degree of confidence prediction of the interaction. The genes encode proteins involved in the assimilation of: (i) galactose; (ii.) D-serine; (iii.) sialic acid; (iv.) L-lactate; (v) maltose; (vi.) sorbitol; (vii.) glycerol; as well as (viii.) components of the galactitolspecific PTS enzyme II; (ix.) C4-dicarboxylate transporter; (X.) dehydrogenase of the proline degradation pathway; (xi.) proteins of the pyruvate metabolism; and (xii.) subunits of the NADH dehydrogenase I 
glycerophosphoryl diester phosphodiesterase and glpK encoding the glycerol kinase were found downregulated in MG1655::фO104, whereas $g l p Q$ together with dhaKLM operon coding for the dihydroxyacetone kinase (glycerol degradation V) in MG1655:: $\phi$ PA8. The gatABC operon encoding components of the (viii) galactitol-specific PTS enzyme II was turned down in the MG1655::\$O104 lysogen and the genes involved in the utilization of ribose, i.e. $r b s D, r b s B, r b s K$ and fructuronate/ glucuronate, i.e. $u x u A B$ and gntP were found significantly downregulated only in the MG1655::\$PA8 lysogen. Furthermore, both Stx2a phage lysogens downregulated $d c t A$ coding for (ix) C4dicarboxylate transporter, responsible for the uptake of fumarate, succinate, L-aspartate etc. under aerobic conditions and putA involved in the $(\mathrm{x})$ proline degradation pathway. Last but not least, MG1655::\$O104 and MG1655::\$PA8 bore downregulated genes involved in the metabolism of (xi) pyruvate, e.g. yji $Y$ encoding a pyruvate: $\mathrm{H}^{+}$symporter, fum $A$ encoding fumarase $\mathrm{A}$, acs encoding acetyl-CoA synthetase, maeB coding for malate dehydrogenase, and $n u о A B C$ coding for the (xii) $\mathrm{NADH}$ dehydrogenase I (nuоAB is found significant only in MG1655:: фO104; Fig. 2 and Additional file 3: Figure S5).
Stx2a phage lysogens display moderate to severe growth defects in minimal medium supplemented with single carbon sources

Given the changes in gene expression, we next determined whether the downregulation of the genes involved in carbon transport and utilization in the Stx2a phage lysogens affected the bacterial phenotype. As a first step, we compared the growth of MG1655::\$O104 and MG1655::\$PA8 in minimal medium supplemented with single carbon sources, i.e. glucose, maltose, L-Lactate, galactose, Nacetylneuraminic acid (sialic acid) and ribose to that of naive MG1655. We found that, as compared to the parental MG1655 strain, the Stx2a phage lysogens exhibited significant differences in the generation time and/or final $\mathrm{OD}_{595}$ after $24 \mathrm{~h}$ of growth with the tested compounds (Table 1, Additional file 3: Figure S6). The Stx2a phage lysogens displayed moderate growth defects in glucose, maltose and sialic acid (reaching up to $46-86 \%$ of the MG1655 final $\mathrm{OD}_{595}$ ) and more severe ones in ribose, galactose and lactate (reaching only $7-43 \%$ of the MG1655 final $\left.\mathrm{OD}_{595}\right)$. We detected no significant difference in the bacterial cell size of the three strains after growth with glucose, galactose and ribose, suggesting that the differences

Table 1 Growth characteristics of MG1655 and the Stx2 lysogens in minimal medium supplemented with singe carbon sources

\begin{tabular}{|c|c|c|c|c|c|}
\hline \multirow[t]{2}{*}{ Strain } & \multirow{2}{*}{$\begin{array}{l}\text { Growth } \\
\text { medium }^{a}\end{array}$} & \multicolumn{2}{|l|}{$\mathrm{OD}=0.4$ pre-culture } & \multicolumn{2}{|l|}{ ON pre-culture } \\
\hline & & 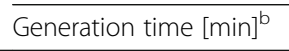 & Final $\mathrm{OD}_{595}{ }^{\mathrm{b}}$ & 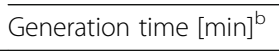 & Final $\mathrm{OD}_{595}{ }^{\mathrm{b}}$ \\
\hline MG1655 & MM glucose & $88 \pm 3$ & $0.41 \pm 0.00$ & $81 \pm 2$ & $0.39 \pm 0.01$ \\
\hline 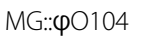 & & $103 \pm 1^{* * *}$ & $0.31 \pm 0.01^{* * *}$ & $106 \pm 3^{* * *}$ & $0.33 \pm 0.02^{* *}$ \\
\hline MG::"ФPA8 & & $106 \pm 2^{* * *}$ & $0.35 \pm 0.00^{* * *}$ & $101 \pm 6^{* *}$ & $0.34 \pm 0.01^{* *}$ \\
\hline MG1655 & MM maltose & $120 \pm 3$ & $0.34 \pm 0.00$ & $111 \pm 1$ & $0.32 \pm 0.00$ \\
\hline MG:: $\varphi 0104$ & & $187 \pm 13^{* * *}$ & $0.23 \pm 0.01^{* * *}$ & $184 \pm 5^{* * *}$ & $0.15 \pm 0.00^{* * *}$ \\
\hline MG:::ФPA8 & & $206 \pm 4^{* * *}$ & $0.24 \pm 0.00^{* * *}$ & $200 \pm 9^{* * *}$ & $0.18 \pm 0.01^{* * *}$ \\
\hline MG1655 & MM L-lactate & $175 \pm 1$ & $0.25 \pm 0.02$ & $170 \pm 1$ & $0.29 \pm 0.01$ \\
\hline 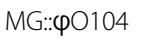 & & $295 \pm 43^{* *}$ & $0.10 \pm 0.01^{* * *}$ & $949 \pm 20^{* * *}$ & $0.05 \pm 0.00^{* * *}$ \\
\hline MG::.甲PA8 & & $218 \pm 7$ & $0.09 \pm 0.00^{* * *}$ & $526 \pm 19 * * *$ & $0.05 \pm 0.01^{* * *}$ \\
\hline MG1655 & MM galactose & $172 \pm 5$ & $0.38 \pm 0.00$ & $166 \pm 2$ & $0.35 \pm 0.00$ \\
\hline MG::. $\varphi 0104$ & & $193 \pm 12^{*}$ & $0.16 \pm 0.00^{* * *}$ & $254 \pm 10^{* *}$ & $0.09 \pm 0.00^{* * *}$ \\
\hline MG::.甲PA8 & & $224 \pm 1^{* *}$ & $0.10 \pm 0.01^{* * *}$ & $319 \pm 27^{* * *}$ & $0.07 \pm 0.00^{* * *}$ \\
\hline MG1655 & MM sialic acid & $102 \pm 2$ & $0.44 \pm 0.00$ & $91 \pm 0$ & $0.43 \pm 0.00$ \\
\hline 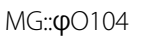 & & $108 \pm 1^{* *}$ & $0.30 \pm 0.00^{* *}$ & $109 \pm 2^{* * *}$ & $0.32 \pm 0.00^{* * *}$ \\
\hline MG:: & & $105 \pm 1$ & $0.30 \pm 0.00^{* *}$ & $114 \pm 3^{* * *}$ & $0.33 \pm 0.00^{* * *}$ \\
\hline MG1655 & MM ribose & $180 \pm 4$ & $0.35 \pm 0.00$ & $177 \pm 4$ & $0.29 \pm 0.00$ \\
\hline MG:.: $\varphi 0104$ & & $456 \pm 9^{* * *}$ & $0.03 \pm 0.00^{* * *}$ & $457 \pm 46^{* * *}$ & $0.02 \pm 0.00^{* * *}$ \\
\hline MG:::ФPA8 & & $791 \pm 61^{* * *}$ & $0.02 \pm 0.01^{* * *}$ & $583 \pm 29^{* * *}$ & $0.02 \pm 0.00^{* * *}$ \\
\hline MG1655 & LB & $32 \pm 1$ & $0.97 \pm 0.02$ & $33 \pm 1$ & $0.94 \pm 0.00$ \\
\hline MG:: $\varphi 0104$ & & $33 \pm 0$ & $0.12 \pm 0.01^{* * *}$ & $33 \pm 1$ & $0.12 \pm 0.01^{* * *}$ \\
\hline MG::. $\varphi P A 8$ & & $32 \pm 1$ & $0.28 \pm 0.02^{* * *}$ & $34 \pm 1$ & $0.27 \pm 0.00^{* * *}$ \\
\hline
\end{tabular}

*The strains displaying significantly different growth characteristics in comparison to MG1655 are marked: ${ }^{*} p<0.05,{ }^{* *} p<0.01,{ }^{* * *} p<0.001$

${ }^{a}$ Cells were grown either in minimal medium (MM) supplemented with $0.2 \%$ of single carbon source or in the nutrient rich LB medium

${ }^{\mathrm{b}}$ The values represent mean and standard error of the mean of three biological replicates 
in the $\mathrm{OD}_{595}$ measurements reflected real differences in the cell number in the cultures (Additional file 3: Figure S7). Interestingly, the observed growth defects were independent of the type of starter culture used, i.e. culture grown to exponential phase (the condition used in RNAseq analysis) or overnight culture (Table 1).

We detected no significant difference in the doubling time among the strains in the nutrient rich LB medium used here as control (Table 1). However, both Stx2a phage lysogens also reached a significantly lower final $\mathrm{OD}_{595}$ in LB than did naive MG1655. We noted that the growth curves of the Stx2a phage lysogens grown in LB displayed a drop in the $\mathrm{OD}_{595}$ shortly after the onset of stationary phase suggesting this transition triggered cell death (Additional file 3: Figure S6). We hypothesized that prophage induction may be responsible for this increase in cell mortality. Consistent with this idea, quantitative PCR analysis revealed an extremely elevated stx2a copy number in MG1655::\$O104 after an overnight incubation in LB in comparison to the exponential starter culture (ca. $7.8 \times 10^{\wedge} 3$ fold increase; Additional file 3: Table S4). In contrast, the $s t \times 2 a$ levels in MG1655::\$O104 grown in minimal medium either did not increase (with glucose) or showed only ca. 30-60 fold elevation (with the rest of the tested carbon courses). Moreover, there was no correlation between the fold increase in the stx $2 a$ copies and the degree of MG1655::\$O104 growth retardation in the corresponding medium. These observations suggested that the detected growth defects of the Stx2a phage lysogens in minimal medium supplemented with the above listed carbon sources could not be attributed to increase in the phage induction frequency.

\section{Phenotype microarrays revealed additional differences in the ability of Stx2a phage lysogens to utilize substrates as a sole source of carbon}

We used the BIOLOG phenotype microarray system and the plate PM1 MicroPlate ${ }^{\mathrm{m}}$ Carbon Sources to further explore the effect of the observed prophage-dependent changes in gene expression on the growth/respiration phenotypes of MG1655::\$O104, MG1655::\$PA8 and naive MG1655 (Fig. 3 and Additional file 3: Figure S8 and Table S5). The BIOLOG PM1 profile obtained with the MG1655 strain was in good agreement with the results from the five independent datasets summarized in the EcoCyc E. coli Database [36]. In our hands, MG1655 showed no or poor respiration with 23 of the 95 tested substrates, while it was able to successfully utilize with different efficiency the remaining 72 substrates (Additional file 3: Figure S8). Both Stx2a phage lysogens exhibited respiration profile significantly different from that of the naive MG1655. In total, 61 and 55 substrates were differentially assimilated by MG1655::\$O104 and MG1655:: $\phi P A 8$, respectively (Additional file 3: Table S5). In the majority of cases, 53/61 in MG1655::\$O104 and 47/55 in MG1655::\$PA8, the Stx2a phage lysogens had a significantly reduced respiration in comparison to naive MG1655 (Fig. 3 and Additional file 3: Figure S8). With regard to our RNA-seq results, the BIOLOG analysis confirmed the reduced respiration of the Stx2a phage lysogens with the substrates D-serine (significant only in MG1655::фO104), L-lactic acid, glycerol, ribose (significant only in MG1655::\$O104), proline, methyl pyruvate, etc. Both MG1655::\$O104 and MG1655::\$PA8 displayed reduced respiration with sorbitol as well, however below the level of significance applied in our analysis. Even though MG1655 displayed initially higher respiration rate with galactose, glucose and maltose, the Stx2a phage lysogens were able to reach the respiration potential of MG1655 and, in the case with maltose, to significantly surpass it (Additional file 3: Figure S8 and Table S5). Interestingly, the MG1655::\$O104 and MG1655::\$PA8 displayed markedly reduced respiration with the majority of gluconeogenic and TCA substrates tested, e.g. amino acids (proline, glutamine, threonine, etc.), nucleosides (thymidine, uridine, adenosine, etc.), carboxylic acids (acetic acid, propionic acid, glyoxylic acid, etc.) and dicarboxylic acids (succinic acid, malic acid, mucic acid, etc.). Of the Stx2a phage lysogens, MG1655::\$O104 exhibited the most drastic growth/respiration defects, assimilating 30 substrates less efficiently than even MG1655::\$PA8 (Additional file 3: Table S5). Both the Stx2a phage lysogens displayed higher respiration with L-arabinose, N-acetyl-D-glucosamine, mannose, L-fucose (significant only in MG1655::\$PA8), xylose, mannitol, fructose, maltose, $\alpha$-D-lactose (significant only in MG1655::фO104) than did naive MG1655 (Fig. 3 and Additional file 3: Figure S8 and Table S5).

\section{Phage encoded factor(s) apart from $\mathrm{Cl}$ and Cro are responsible for the carbon utilization phenotypes of Stx2a phage lysogens}

The data presented in this study were obtained with two independent Stx2a phage lysogens with distinct integration sites $[4,33]$, indicating that phage encoded factor(s) rather than mutations in the bacterial chromosomal backbone mediate the changes in carbon utilization of MG1655::\$O104 and MG1655::\$PA8 in comparison to naive MG1655. Moreover, since the majority of the changes in the transcriptome and phenotype were detected in both lysogens, the factor(s) responsible for them should be shared between these phages. Besides their normal roles in regulating phage transcription, the $\mathrm{CII}$ and Cro proteins in other Stx2a-encoding phages have already been shown to regulate the expression of some bacterial host genes [30-32]. The фO104 and фPA8 apparently do not encode a CII protein and express only the $\mathrm{CI}$ repressor and the Cro anti-repressor 


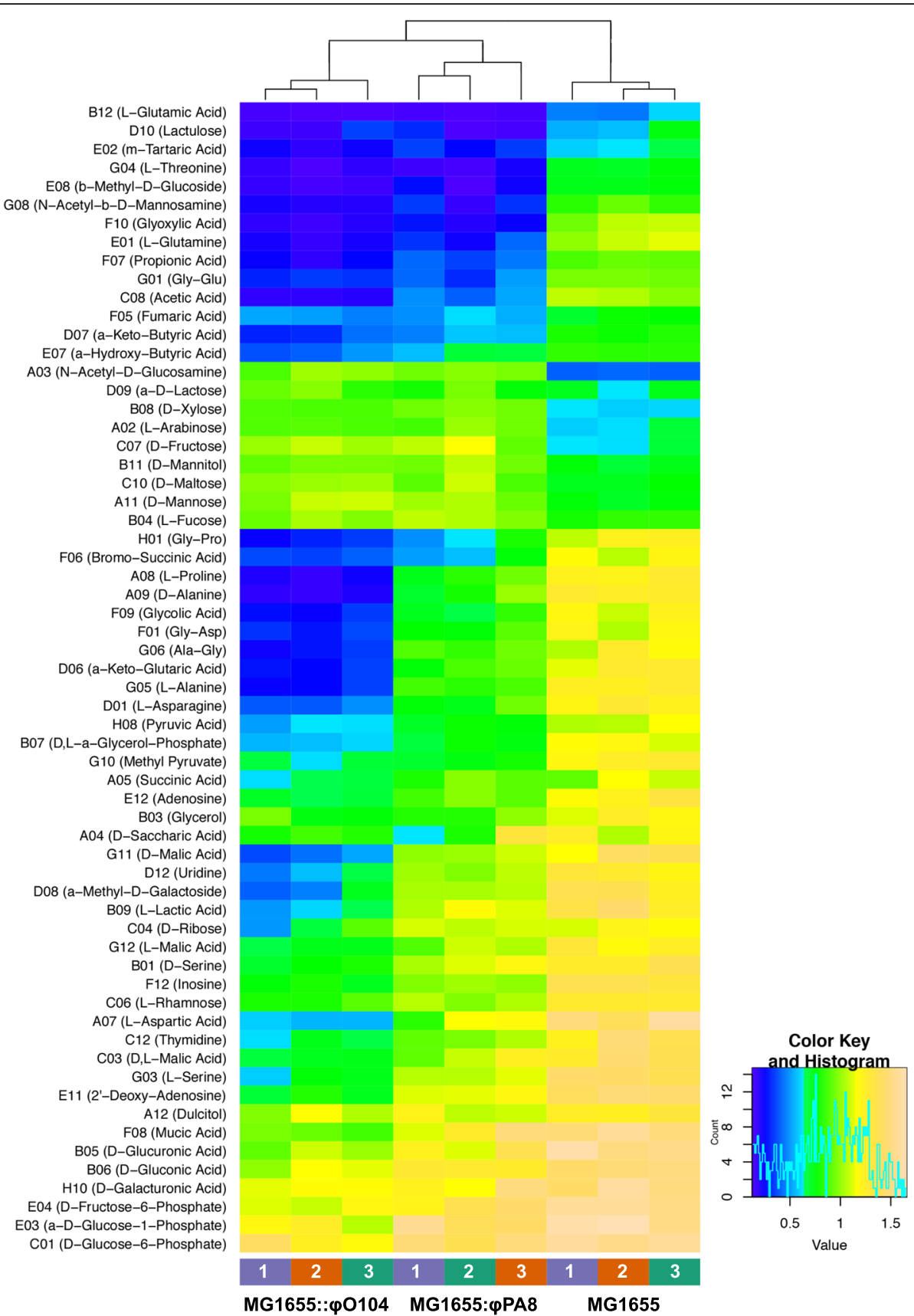

Fig. 3 Heatmap of the respiration potential of naive MG1655 and the Stx2a phage lysogens analyzed with the BIOLOG PM1 plate. The heatmap shows a subset of substrates, with which the Stx2a phage lysogens display significantly reduced or increased respiration in comparison to naive MG1655. Three biological replicates per strain were analyzed. The degree of respiration with each substrate is color coded based on the provided color key. The tree on top of the map shows the relationship between the analyzed samples based on their overall respiration pattern

[33]. The sequences of these two proteins are $100 \%$ identical between the two phages. Our transcriptome data showed that these regulators were expressed on the RNA level, with $c I$ being the one more actively transcribed in both lysogens (Additional file 3: Table S6), a feature that was in agreement with its function in maintaining lysogeny [37]. In order to determine whether these phage regulators contribute to the observed changes in carbon source utilization, we cloned $c I$ and cro genes into the low copy pWKS30 vector under the control of their native promoters and validated their expression on the mRNA level (see Methods and Additional file 3: Table S7). We found that MG1655 bearing either pWKS30-cI or pWKS30-cro exhibited no 
significant differences in the doubling time and final $\mathrm{OD}_{595}$ detected in growth experiments with minimal medium supplemented with $0.2 \%$ glucose, maltose, Llactate, galactose, glycerol and ribose in comparison to cells with empty vector (Additional file 3: Figure S9). As measured using the BIOLOG PM1 plate, we found that the strains carrying these plasmids exhibited virtually identical respiration profile as did naive MG1655 (Additional file 3: Figure S10). These results indicated that phage encoded factor(s) apart from CI and Cro are responsible for the carbon utilization phenotypes detected in MG1655::\$O104 and MG1655::фPA8.

\section{Discussion}

Here, we analyzed the effects of the carriage of two closely sequence related Stx2a phages: $\phi 0104$ from the exceptionally pathogenic 2011 E. coli O104:H4 outbreak strain and $\phi \mathrm{PA} 8$ from an E. coli $\mathrm{O} 157: \mathrm{H} 7$ isolate on E. coli $\mathrm{K}-12$ host. Both quantitative RNA-seq analysis and phenotypic investigations revealed a profound impact of the Stx phage carriage on MG1655 carbon source utilization.

The strong correlation between our transcriptome and phenotype analyses indicates that the majority of detected changes in gene expression in the Stx2a phage lysogens are robust as they apparently result in stable phenotypic changes. The only major exception to this correlation is the observed lack of significant reduction in the respiration detected with sorbitol, galactose, glucose and maltose in the BIOLOG assay. However, the finding that growth in these carbon sources is accompanied by initial growth retardation of the lysogens in comparison to naive MG1655 suggests that in this case the prophage-dependent alteration in host metabolism occurs only transiently, i.e., it is a growth phase-specific phenotype. The discrepancy between the results of the BIOLOG microarrays with glucose, maltose and galactose and that of the minimal medium experiments with these carbon sources suggests that the growth retardation/reduced respiration phenotypes are more pronounced after a shift from nutrient rich to poor medium (Additional file 3: Figures S6 and S8).

We wished to gain insight into how Stx prophage carriage affects $E$. coli host cell transcription. To this end, we compared our RNA-seq results with the previously published high throughput data sets obtained from $E$. coli host lysogens bearing the Stx 2 a phages $\phi M i n 27$ or $\phi 24_{B}[29$, 30]. We find that there is limited to no correlation between the transcriptional effects of $\phi \mathrm{O} 104$ or $\phi \mathrm{PA} 8$ with cells bearing either of these two Stx2a phages. We suggest that the sequence heterogeneity of these Stx2a phages plays the major role in determining the differences in the transcriptome between these individual strains. Notably, $\phi$ Min 27 and $\phi 24_{\mathrm{B}}$ share only limited sequence similarity to the Stx2a phages used in our analysis $(59-64 \%$ query coverage, 97-98\% identity). However, differences in the methodologies used and/or experimental set up may also contribute to the discrepancies. For example, the study on the $\phi$ Min27 impact on host transcription is based on microarray gene expression data [29]. Similarly, VesesGarcia et al. applied next generation sequencing in combination with an SOS-triggered phage induction in order to select for the $\phi 24_{\mathrm{B}}$ lysogeny-specific transcriptional response. They excluded all differentially regulated genes detected upon norfloxacin treatment (phage induction) from their analysis [30]. This approach may mask stable changes in the host gene expression, which might be present both under phage lysogeny and in the recovery phase upon the norfloxacin treatment, repressing expression of genes involved in aerobic metabolism, while stimulating those involved in anaerobic respiration.

Our RNA-seq data show that carriage of the Stx2a phages $\phi \mathrm{O} 104$ or $\phi \mathrm{PA} 8$ results in a reprogramming of the host cell's central metabolism (Fig. 2, Additional file 3: Figures S3 and S5 and Tables S2 and S3). This reprogramming might be aimed at allowing $E$. coli to grow and compete better under anaerobic conditions. On one side Stx2a prophage carriage represses (directly or indirectly) the expression of several genes involved in aerobic carbon metabolism. These include genes that encode the TCA enzymes fumarase A (fumA) and malate dehydrogenase $(m a e B)$ and subunits of the NADH dehydrogenase I (i.e. $n$ nu $A B C$ ), which is part of the oxidative phosphorylation pathway. On the other hand, Stx2a phage carriage activates genes encoding enzymes involved in fermentative/ anaerobic carbon metabolism (i.e., ldhA, ace and ackA) and NADH dehydrogenase II (i.e., $n d h$ ), which in comparison to NADH dehydrogenase I recycles NADH without generating an electrochemical gradient and with less efficiency [38].

Significantly, when accompanied by upregulation of $n d h$, the downregulation of the nuo genes would promote assembly of a respiratory chain that is not optimal for the efficient oxidation of $\mathrm{NADH}$ to $\mathrm{NAD}^{+}$. This change should lead to NADH accumulation, which in turn would reduce TCA cycle enzyme activity via the allosteric inhibition of malate dehydrogenase [39] and citrate synthase [40] (enzymes shared between TCA and glyoxylate cycle). Moreover, nuo mutants, which grow poorly on acetate as a single carbon source, are also known to be unable to efficiently grow on amino acids, whose metabolism is TCA cycle-dependent. This growth defect presumably results from suppression of TCA cycle activity due to high $\mathrm{NADH} / \mathrm{NAD}^{+}$[41].

Our results support this idea, i.e., we find that the Stx2a phage lysogens have a decreased ability to utilize TCA cycle and gluconeogenic substrates, e.g. amino acids, carboxylic and dicarboxylic acids (Fig. 3 and Additional file 3: Figure S8). This increase in the availability 
of intracellular NADH in the Stx2a phage lysogens should also lead to a shift to fermentative/anaerobic carbon metabolism. Indeed, it was reported that artificially increasing the availability of $\mathrm{NADH}$ during aerobic growth induces the production of fermentation end products (e.g. ethanol, lactate) [42].Consistent with this prediction, we find that expression of $\operatorname{ldh} A$, ace and ack $A$ is upregulated in the Stx2a phage lysogens.

Fermentation products and elevated NADH/NAD ${ }^{+}$ratios are linked to the level of phosphorylated and active form of the two component system ArcAB [43-45], which is one of the global regulators coordinating gene expression to changes in $\mathrm{O}_{2}$ availability [46]. Therefore, it comes as no surprise that there are multiple overlaps between the Stx2a phage-carriage-dependent downregulated genes detected here and the ArcA regulon [47]: nuo, the TCA cycle genes fumA and maeB, genes involved in carbon source transport and metabolism $g l p D$, $m g l B$, putA, lldP and others. The above discussed Stx phage-dependent changes in the gene expression geared at reprogramming E. coli $\mathrm{K}-12$ metabolism are summarized in Fig. 4. It should be nevertheless noted that our model explains the majority but not all the changes detected in our analysis.

The ability of both commensal and pathogenic E. coli to colonize the intestine is governed by the relative efficiencies with which a given strain can use a particular carbon source, which is, in turn, determined by the activities of a cell's central metabolic pathways [48]. For example to efficiently colonize streptomycin-treated mice, MG1655 relies on its ability to metabolize N- acetylneuraminic acid, N-acetyl-D-glucosamine, arabinose, gluconate and fucose [49]. Our results show that carriage of either $\phi \mathrm{O} 104$ or $\phi \mathrm{PA} 8$ substantially decrease MG1655's ability to grow on $\mathrm{N}$-acetylneuraminic acid and gluconate while increasing its ability to utilize the other sugars (Table 1 and Fig. 3). If the results of our in vitro studies accurately predict what sugars a cell can utilize in vivo, the Stx2a phage lysogens should outcompete naive MG1655 in niches with available arabinose, fucose and $\mathrm{N}$-acetyl-D-glucosamine, while be readily eliminated in the ones with $\mathrm{N}$-acetylneuraminic acid and gluconate. Interestingly, certain EHEC strains carry additional functional nanS-homologues alleles, which are prophage-encoded [50-52]. In respect to our data, multiple nanS copies would be beneficial to compensate for potential Stx phage-dependent decrease in the ability to utilize $\mathrm{N}$-acetylneuraminic acid due to downregulation of the native nan operons.

Even though E. coli grows best on sugars (mono- and disaccharides), it can also grow on amino acids and other substrates for the TCA cycle [48]. However, TCA cycle and gluconeogenic mutants exhibit no defects in colonization of the streptomycin-treated mouse intestine and thus exclude a major role of amino acids catabolism in colonization of MG1655 [53]. In addition, MG1655 use glycolytic but not gluconeogenic substrates for growth in this mouse model when fed alone or together with E.coli O157:H7 [54]. However, both aerobic and anaerobic respiration mutants of MG1655 and E. coli O157:H7 are eliminated by competition with wild type strains and respiration of oxygen provides greater

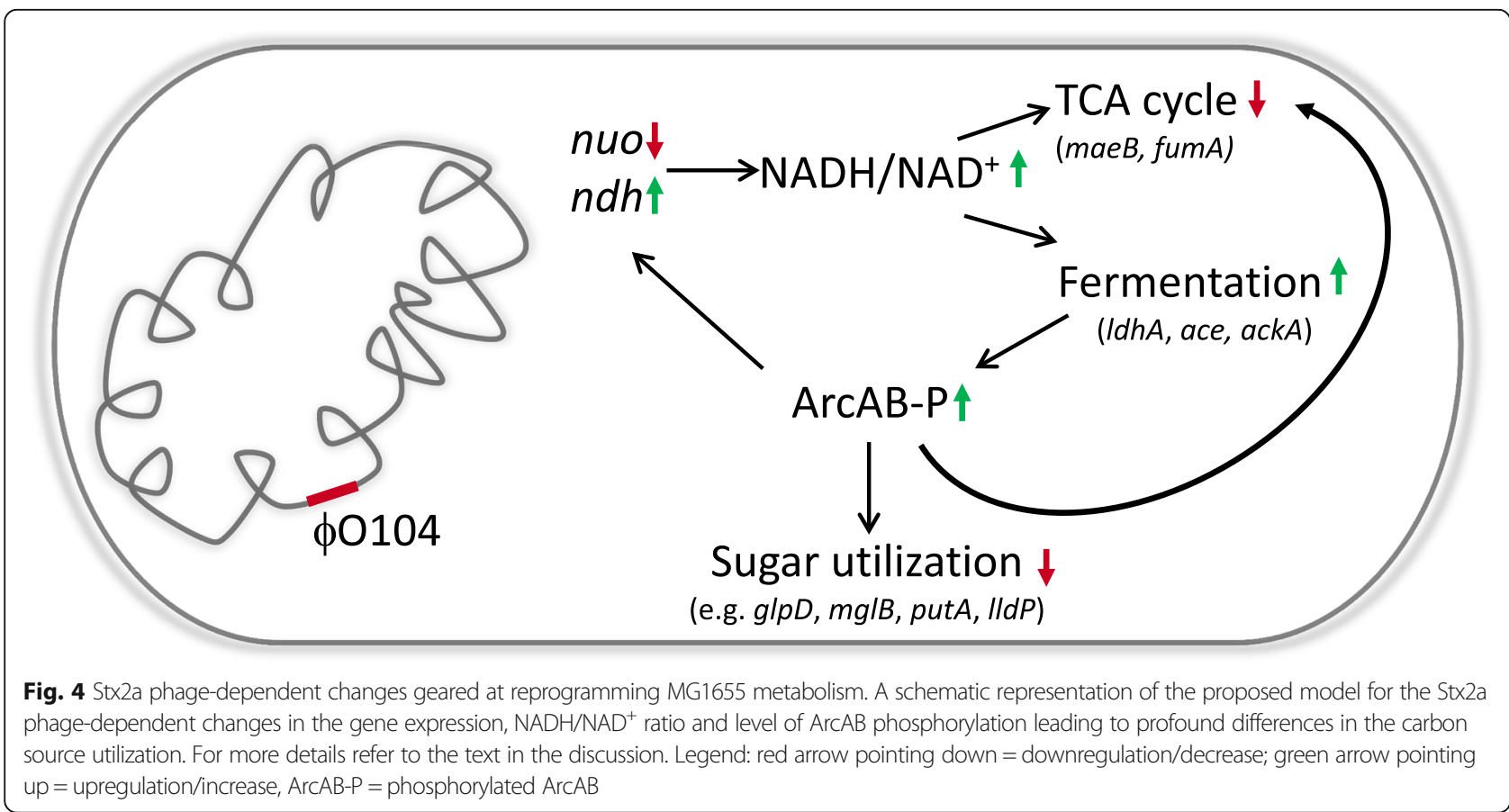


colonization advantage than anaerobic respiration in the streptomycin-treated mouse intestines to both $E$. coli species $[55,56]$. Therefore, it remains unclear if the decreased potential of the Stx2a phage lysogens to utilize amino acids, dicarboxylic acids and other gluconeogenic substrates detected here under aerobic conditions (Fig. 3) would compromise their colonization efficiency in comparison to naive MG1655.

The downregulation of sugar import and catabolism, as well as of aerobic metabolism (TCA cycle and oxidative phosphorylation) might in addition contribute to the survival of the Stx2a phage lysogen population, e.g. by stimulating persister cell formation [57, 58]. Persister cells are genetically unaltered subpopulations of cells that are locked into "dormant, non-dividing phase" and can thus survive otherwise lethal doses of antibiotics [59]. Intriguingly, among the upregulated genes in both MG1655:: фO104 and MG1655::\$PA8 we identified genes, which have previously been described to be involved in the formation of persister cells, i.e. tis $B$, encoding the toxin peptide of Type I toxin-antitoxin system [60] and $l d h A$ [61]. The maintenance of an increased number of persisters in otherwise favorable growth conditions may be especially important for Stx phage lysogens, as a stress depended induction of the phage might otherwise result in a complete collapse of the bacterial population. As other potential susceptible hosts would experience the same stress in such an environment, stable lysogenization of a new host would be impossible and thus eventually endanger the long-term survival of the phage itself.

Our heterologous expression experiments in MG1655 revealed that phage encoded factor(s) apart from $\mathrm{CI}$ and Cro are responsible for the carbon utilization phenotypes detected in MG1655::\$O104 and MG1655::фPA8. Experiments involving systematic heterologous expression of phage regions in MG1655 or phage truncation experiments in the Stx2a phage lysogens will be necessary to discover the so far unknown regulatory determinant(s). Determining these factor(s) will facilitate the evaluation of the biological meaning of the here described Stx2a phage-dependent effects on the bacterial host and in particular if these traits are shared with other phages or they are rather Stx2a phage-, or even \$O104- and фPA8-specific effects.

\section{Conclusion}

Here, we use quantitative RNA-seq to demonstrate that Stx2a phage carriage has a previously unforeseen strong impact on $E$. coli $\mathrm{K}-12$ host gene expression governing carbon source transport and metabolism. Subsequent phenotypic tests including microarrays show that the lysogeny is indeed associated with the according changes in the carbon source utilization. Thus, our work confirms previous observations that Stx phage carriage not only provides the bacterial host with the ability to produce Stx, but that it can also have an impact on its gene expression and phenotype. The strong correlation between our transcriptome and phenotype analyses indicate that the majority of detected changes in the gene expression patterns of the analyzed Stx2a phage lysogens are robust as they result in stable phenotypic changes. The Stx2a prophage appears to reprogram the carbon metabolism of its bacterial host by turning down aerobic metabolism in favour of mixed acid fermentation. This results in the decreased ability of Stx2a phage lysogens to utilize TCA cycle and gluconeogenic substrates, e.g. amino acids, carboxylic and dicarboxylic acids, and other carbon sources. In addition, the Stx2a phage carriage apparently leads to an enhanced respiration with several sugars that comprise part of the intestinal mucus.

To our knowledge, this is the first study that describes that the Stx phage carriage results in profound changes in metabolism and carbon source utilization potential of the host and that these changes are very likely based on Stx phage-dependent reprogramming of the host cell's transcriptional profile. The phage factor(s) that are responsible for these dramatic differences in the host's transcriptome and phenotype are, as yet, unidentified.

\section{Methods \\ Strains}

The E. coli K-12 strain MG1655 [62] was used as the recipient for the $\phi \mathrm{O} 104$ and $\phi \mathrm{PA} 8$ Stx2a phages. Phages $\phi \mathrm{O} 104$ and $\phi \mathrm{PA} 8$ were isolated from the parental EHEC strains by treating exponential phase cells grown in LB plus $10 \mathrm{mM} \mathrm{MgSO}_{4}$ with $5 \mu \mathrm{g} / \mathrm{mL}$ mitomycin C. After an additional $4 \mathrm{~h}$ of growth at $37^{\circ} \mathrm{C}$ to allow for phage growth and cell lysis, an aliquot of the lysate was extracted with $\mathrm{CHCl}_{3}$ and the cellular debris pelleted by centrifugation at $13,000 \mathrm{~g}$. Dilutions of the phage-containing supernatants were spotted on a lawn of MG1655 growing in soft agar overlaid on an LB agar plate and the plates incubated overnight at $37^{\circ} \mathrm{C}$ to allow the formation of phage plaques. Putative lysogens were picked from the center of these plaques and streaked on an LB agar plate. The successful lysogenization was verified by colony PCR with primers PB_1 \& PB_2 binding within stx2a (Additional file 3: Table S8). The insertion of $\phi \mathrm{O} 104$ in $w r b A$ of MG1655 (MG1655:: фO104) was confirmed by PCR with primers PB_4 \& PB_5 and of фPA8 in argW (MG1655:: фPA8) with PB_7 \& PB_8.

\section{Bacterial growth and RNA preparation for transcriptome analysis}

The bacterial growth and RNA preparation for the RNA-seq experiment were performed as previously described [63] with the following modifications. The experiments were performed with 3 biological replicates per strain. Overnight cultures were diluted till $\mathrm{OD}_{600}$ of 
0.005 in LB medium $(10 \mathrm{~g} / \mathrm{L}$ tryptone, $5 \mathrm{~g} / \mathrm{L}$ yeast extract, $5 \mathrm{~g} / \mathrm{L} \mathrm{NaCl}$ ) and cells were grown at $37^{\circ} \mathrm{C}, 180$ rpm to an $\mathrm{OD}_{600}$ of 0.4-0.6. After the treatment with stop solution ( $5 \%$ phenol $/ 95 \%$ ethanol), cells pellets were immediately lysed with cell lysis buffer $(85 \mathrm{mg} / \mathrm{mL}$ lysozyme in TE buffer, $\mathrm{pH} 8$ ). One $\mathrm{mL}$ of Trizol reagent was added and samples were stored at $-20{ }^{\circ} \mathrm{C}$ till the RNA isolation protocol was resumed.

RNA-seq: cDNA library construction, sequencing and data analysis

RNA preparations were treated with RiboZero (Illumina) and converted to cDNA libraries using NEBNext Ultra Directional RNA Library Kit following the manufacturers' instructions. cDNA libraries were sequenced on NextSeq 550 System using NextSeq 500/550 Mid-Output kit (Illumina). The quality of the raw sequenced reads was checked using FastQC v.0.11.2 [64]. Adapters were removed using cutadapt v.1.14.1 [65] and reads were reverse complemented with FASTX v.0.0.14 [66]. Data was mapped to the reference genomes of $E$. coli MG1655 (U00096.3), фPA8 (KP682374.1) and $\phi O 104$ (3,256,115 to 3,317,011 from NC_018658.1) using READemption v.0.4.3 [67] and segemehl v.0.2.0 [68]. Differential gene expression analysis was performed with READemption and DESeq2 v.1.16.1 package in $R$ [69]. Changes in the gene expression $\geq 1.5$ fold $(\log 2$ fold $\geq 0.58$ ) with adjusted $p$ value for multiple comparison (padj) $<0.1$ were considered significant.

Growth kinetics, cell size, Stx2a phage presence and stx2a gene copy measurements in minimal medium supplemented with single carbon sources

Overnight or exponential $\left(\mathrm{OD}_{600}=0.4-0.6\right)$ starter $\mathrm{LB}$ cultures were diluted 1:200 in $\mathrm{N}$-C- minimal medium [70] with $10 \mathrm{mM}$ ammonium chloride as the nitrogen source and $0.2 \%$ of single carbon source. The following carbon sources were used: glucose (Sigma, \# G7528), maltose monohydrate (Sigma, \# M5895), sodium Llactate (Sigma, \#71718), galactose (Sigma, \#G0750), Nacetylneuraminic acid (Sigma, \#A2388) and ribose (Sigma, \# R7500). The growth kinetic measurements over $24 \mathrm{~h}$ were performed as previously described [71]. Due to the use of LB starter cultures the strains were characterized by diauxic growth curves in minimal medium. The minimal doubling time with each carbon source was calculated using the linear region of the second phase of the growth curve.

After the $24 \mathrm{~h}$ incubation, the samples were further analyzed by measuring the cell size of the strains, verifying the presence of the Stx2a phage and determining the stx $2 a$ copy number in the lysogens. The cell size of the strains was controlled by light microscopy. Briefly, $100 \mu \mathrm{L}$ of the samples grown in minimal medium with glucose, galactose and ribose were mixed with $800 \mu \mathrm{L}$ PBS and $100 \mu \mathrm{L} \mathrm{37 \%} \mathrm{formaldehyde.} \mathrm{After} 1 \mathrm{~h}$ incubation at room temperature, $5 \mu \mathrm{L}$ were spotted on a slide and visualized using Nikon Eclipse $\mathrm{Ci}$ microscope and 40x magnification. The cell size was determined with the NIS-Elements D 4.60.00 imaging software. The presence of the Stx2a phage in the lysogens was routinely controlled by diluting the samples to $10^{\wedge} 6$ or $10^{\wedge} 7$ and plating, followed by colony PCR with stx $2 a$ primers (PB_1 and PB_2) to screen 20 randomly selected colonies per growth condition. To determine semi-quantitatively the stx $2 a$ copy numbers in MG1655::\$O104 after the growth in minimal medium, $50 \mu \mathrm{L}$ were boiled for $10 \mathrm{~min}$ and used as template for quantitative PCR (Bio-Rad) with stx2a (PB_1 \& PB_2) and gapA (PB_9 \& PB10) primers (Additional file 3: Table S8). The linearity of the primers was tested by 10 fold serial dilutions of gDNA template from E. coli O104:H4. Data was analyzed using the BioRad CFX Manager 3.1. The increase in the stx2a copies was calculated using the $\Delta \Delta \mathrm{Ct}$ method with gap $A$ being the control gene and the starter culture (exponential LB culture) set as control sample.

\section{Genome comparisons of Stx2a phages}

The phages $\phi \mathrm{O} 104$ and $\phi \mathrm{PA} 8$ were aligned using Mauve with default parameters. The similarities (\% query coverage, \% identity) between the phage genomes were analyzed using NCBI blastn [72]. The phages $\phi 24 \mathrm{~B}$ (HM208303.1) and фMin27 (EU311208) were additionally included in the blastn analysis.

\section{BIOLOG phenotype microarrays: workflow and data analysis}

The BIOLOG phenotype microarray experiments with PM1 carbon sources were performed following the manufacturer's instruction with the following modification: the glycerol stocks of the strains were plated on Columbia Blood Agar (Oxoid). The growth kinetics measurements of the PM1 plates were done in a TECAN Infinite F200 instrument by determining the $\mathrm{OD}_{595}$ every $15 \mathrm{~min}$ for $24 \mathrm{~h}$ at $37^{\circ} \mathrm{C}$ without shaking. BIOLOG data was analyzed and visualized using the opm package v.1.3.77 for R [73]. Briefly, after importing of kinetic raw data and metadata integration, descriptive curve parameters (lag phase $(\lambda)$, respiration rate $(\mu)$, maximum curve height (A) and Area Under the Curve (AUC)) were estimated using do_aggr function via spline-fitting. Statistical analysis of growth curves of the three strains (naive MG1655, MG1655::фO104 and MG1655::\$PA8) in three independent repetitions was performed with opm_mcp method, which internally accounts for multiple comparisons. 


\section{Heterologous expression of $\mathrm{Cro}$ and $\mathrm{Cl}$ in MG1655}

The Stx2a phage regions from position -105 to +51 relative to the annotated cro ORF and from position -88 to + 90 relative to the annotated $c I$ ORF (encompassing their predicted promoter regions) were amplified from total DNA from MG1655::\$O104 using the Phusion Polymerase (Thermo Scientific) and the primers PB_11 \& 12 and PB_13 \& 14 (Additional file 3: Table S8), respectively. The fragments were ligated into the low copy number plasmid pWKS30 [74] linearized with the restriction enzyme SmaI and transformed in chemically competent NEB 5-alpha $E$. coli cells (NEB). Plasmids carrying the constructs in the same orientation (cloned ORFs downstream of the lac promoter in pWKS30) were selected by colony PCR using primers M13_rev \& PB_12 or PB_13. Sanger sequencing was used to verify the correct sequence of the cloned constructs. The plasmids pWKS-cI and pWKS-cro were then transformed in electrocompetent MG1655 cells. The expression of $c I$ and cro in MG1655 pWKS-cI and MG1655 pWKS-cro, respectively, was verified by reverse transcription polymerase chain reaction (RT-PCR) in total RNA isolated form cells grown to exponential phase in LB or minimal medium supplemented with $0.2 \%$ glucose. RTPCR was performed with OneStep RT-PCR kit (Qiagen) and the primers $\mathrm{PB} \_15 \& 16(\mathrm{cI})$ and PB_17\&18 (cro).The relative normalized expression of $c I$ and $c r o$ was calculated using the $\Delta \Delta \mathrm{Ct}$ method with gapA being the control gene (quantified with primers PB_9\&PB_10) and MG1655:: фO104 set as a control sample.

\section{Statistical analysis and data visualization}

Statistical analysis of data other than RNA-seq and BIOLOG datasets was done using $\mathrm{R}$ v.3.4.0 computing environment [75]. Welch two sample t-test was used to compare the means of two groups of samples. ANOVA was used to assess the difference between more than two sample groups. Pairwise comparisons between groups were performed using t-tests with corrections for multiple testing using the Holm method. Figures were created using opm and ggplot2 [76] packages in $\mathrm{R}$ and Adobe Photoshop CC 2017.

\section{Additional files}

Additional file 1: DESeq2 results using MG1655 as the reference librabry (divisor) and MG1655::40104 as the comparison library (numerator). (XLSX 633 kb)

Additional file 2: DESeq2 results using MG1655 as the reference librabry (divisor) and MG1655::. PPA8 as the comparison library (numerator). (XLSX 697 kb)

Additional file 3: Table S1. Overview of sequenced and mapped reads. Figure S1. Principal component analysis (PCA). Table S2. Up- and downregulated genes in MG1655:: PO104 in comparison to naive MG1655. Table S3. Up- and downregulated genes in MG1655:: PPA8 in comparison to naive MG1655. A. Upregulated genes. B. Downregulated genes. Figure S2. Genome alignment of $\varphi 0104$ and $\varphi$ PA8. Figure S3. Interaction analysis of the genes found upregulated in the Stx2 lysogens. Figure S4. Stx2 phage carriage enhances FliC expression and motility. Figure S5. Interaction analysis of the genes found downregulated in MG1655::.9PA8. Figure S6. Growth phenotypes of MG1655 and the Stx2 lysogens in minimal medium supplemented with singe carbon sources. Figure S7. Bacterial size in growth experiments with minimal medium supplemented with single carbon sources. Table S4. Semi-quantitative determination of stx2 copy number in MG1655:: $\varphi$ O104. Figure S8. Kinetic measurements of the respiration potential of the strains using BIOLOG PM1 MicroPlate ${ }^{T M}$ Carbon Sources. Table S5. Statistical comparisons of the respiration potential of the strains using BIOLOG PM1 MicroPlate ${ }^{\text {TM }}$ Carbon Sources. Table S6. Normalized counts of sequencing reads mapped to A. $\varphi$ O104-encoded genes and B. $\varphi$ PA8-encoded genes. Table S7. Verifying the expression of $\mathrm{Cl}$ and $\mathrm{cro}$ in MG1655 pWKS-Cl and MG1655 pWKS-cro, respectively. Figure S9. Growth phenotypes of $\mathrm{cl}$ and cro expression in MG1655 in minimal medium supplemented with single carbon sources. Figure S10. Heatmap of the respiration potential of MG1655 pWKS30, MG1655 pWKS30-cl and MG1655 pWKS30-cro. Table S8. Primers used in this study. (DOCX $4959 \mathrm{~kb}$ )

\section{Abbreviations}

E. coli: Escherichia coli; EAEC: Enteroaggregative Escherichia coli; EHEC: Enterohemorrhagic Escherichia coli; HC: Hemorrhagic colitis; HUS: Hemolytic uremic syndrome; LEE: Locus of enterocyte effacement; RNAseq: RNA sequencing; RT-PCR: Reverse transcription polymerase chain reaction; Stx: Shiga toxin

\section{Acknowledgements}

We thank Helge Karch for discussion and critical reading of the manuscript.

\section{Authors' contributions}

$\mathrm{PB}, \mathrm{UD}, \mathrm{GBK}$ and. $\mathrm{AM}$ led the project. PB, MB, GBK and AM designed experiments. $P B, N H$, and GBK performed experiments. PB, IUK, MB, UD, GBK and AM analyzed data. IUK performed bioinformatics analysis, statistics and data visualization. PB, MB and GBK wrote the manuscript. All authors participated in manuscript preparation and approved the final manuscript.

\section{Funding}

This work was funded by the Deutsche Forschungsgemeinschaft (DFG, German Research Foundation) - project number 276606594, ME3205/5-1, SFB1009 B04 and SFB1009 B05. The funding body had no role in the design of the study and collection, analysis, and interpretation of data and in writing the manuscript.

\section{Availability of data and materials}

The sequencing data has been deposited in the NCBI's Gene Expression Omnibus [77] and can be accessed through GEO Series accession number GSE126710. Additional information and data are available upon contacting the corresponding author.

Ethics approval and consent to participate Not applicable.

\section{Consent for publication}

Not applicable.

\section{Competing interests}

The authors declare that they have no competing interests.

\section{Author details}

${ }^{1}$ Institute of Hygiene, University of Münster, Münster, Germany. ${ }^{2}$ Institute of Bioinformatics, University of Münster, Münster, Germany. ${ }^{3}$ Department of Biological Sciences, University at Buffalo, Buffalo, USA.

Received: 29 March 2019 Accepted: 10 June 2019 Published online: 17 June 2019

\section{References}

1. Karch H, Tarr PI, Bielaszewska M. Enterohaemorrhagic Escherichia coli in human medicine. Int J Med Microbiol. 2005;295(6-7):405-18. 
2. Corrigan JJ, Boineau FG. Hemolytic-uremic syndrome. Pediatr Rev. 2001; 22(11):365-9.

3. Mellmann A, Bielaszewska M, Kock R, Friedrich AW, Fruth A, Middendorf B, et al. Analysis of collection of hemolytic uremic syndrome-associated enterohemorrhagic Escherichia coli. Emerg Infect Dis. 2008;14(8):1287-90.

4. Bielaszewska M, Mellmann A, Zhang W, Kock R, Fruth A, Bauwens A, et al. Characterisation of the Escherichia coli strain associated with an outbreak of haemolytic uraemic syndrome in Germany, 2011: a microbiological study. Lancet Infect Dis. 2011;11(9):671-6.

5. Schimmer B, Nygard K, Eriksen HM, Lassen J, Lindstedt BA, Brandal LT, et al. Outbreak of haemolytic uraemic syndrome in Norway caused by stx2positive Escherichia coli 0103:H25 traced to cured mutton sausages. BMC Infect Dis. 2008;8:41.

6. Tarr PI, Gordon CA, Chandler WL. Shiga-toxin-producing Escherichia coli and haemolytic uraemic syndrome. Lancet. 2005;365(9464):1073-86.

7. Scheutz F, Teel LD, Beutin L, Pierard D, Buvens G, Karch H, et al. Multicenter evaluation of a sequence-based protocol for subtyping Shiga toxins and standardizing Stx nomenclature. J Clin Microbiol. 2012;50(9):2951-63.

8. Bai X, Fu S, Zhang J, Fan R, Xu Y, Sun H, et al. Identification and pathogenomic analysis of an Escherichia coli strain producing a novel Shiga toxin 2 subtype. Sci Rep. 2018;8(1):6756.

9. FAO/WHO STEC Expert Group. Hazard identification and characterization: criteria for categorizing Shiga toxin-producing Escherichia coli on a risk basis. J Food Prot. 2019;82(1):7-21.

10. Friedrich AW, Bielaszewska M, Zhang WL, Pulz M, Kuczius T, Ammon A, et al. Escherichia coli harboring Shiga toxin 2 gene variants: frequency and association with clinical symptoms. J Infect Dis. 2002;185(1):74-84.

11. O'Brien AD, Newland JW, Miller SF, Holmes RK, Smith HW, Formal SB. Shigalike toxin-converting phages from Escherichia coli strains that cause hemorrhagic colitis or infantile diarrhea. Science. 1984;226(4675):694-6.

12. Karch H, Schmidt H, Janetzki-Mittmann C, Scheef J, Kroger M. Shiga toxins even when different are encoded at identical positions in the genomes of related temperate bacteriophages. Mol Gen Genet. 1999;262(4-5):600-7.

13. Kimmitt PT, Harwood CR, Barer MR. Toxin gene expression by Shiga toxinproducing Escherichia coli: the role of antibiotics and the bacterial SOS response. Emerg Infect Dis. 2000;6(5):458-65.

14. Waldor MK, Friedman DI. Phage regulatory circuits and virulence gene expression. Curr Opin Microbiol. 2005;8(4):459-65.

15. Smith DL, Rooks DJ, Fogg PC, Darby AC, Thomson NR, McCarthy AJ, et al. Comparative genomics of Shiga toxin encoding bacteriophages. BMC Genomics. 2012;13:311.

16. Rahman M, Nabi A, Asadulghani M, Faruque SM, Islam MA. Toxigenic properties and stx phage characterization of Escherichia coli $\mathrm{O} 157$ isolated from animal sources in a developing country setting. BMC Microbiol. 2018;18(1):98.

17. Herold S, Karch H, Schmidt H. Shiga toxin-encoding bacteriophages-genomes in motion. Int J Med Microbiol. 2004;294(2-3):115-21.

18. Kampmeier S, Berger M, Mellmann A, Karch H, Berger P. The 2011 German enterohemorrhagic Escherichia Coli O104:H4 outbreak-the danger is still out there. Curr Top Microbiol Immunol. 2018:416:117-48.

19. Brzuszkiewicz E, Thurmer A, Schuldes J, Leimbach A, Liesegang H, Meyer FD, et al. Genome sequence analyses of two isolates from the recent Escherichia coli outbreak in Germany reveal the emergence of a new pathotype: Entero-aggregative-Haemorrhagic Escherichia coli (EAHEC). Arch Microbiol. 2011;193(12):883-91.

20. Rasko DA, Webster DR, Sahl JW, Bashir A, Boisen N, Scheutz F, et al. Origins of the E. coli strain causing an outbreak of hemolytic-uremic syndrome in Germany. N Engl J Med. 2011;365(8):709-17.

21. Feng P, Lampel KA, Karch H, Whittam TS. Genotypic and phenotypic changes in the emergence of Escherichia coli O157:H7. J Infect Dis. 1998; 177(6):1750-3.

22. Eichhorn I, Heidemanns $K$, Ulrich RG, Schmidt $H$, Semmler T, Fruth $A$, et al. Lysogenic conversion of atypical enteropathogenic Escherichia coli (aEPEC) from human, murine, and bovine origin with bacteriophage Phi3538 $\Delta$ stx2:: cat proves their enterohemorrhagic E. coli (EHEC) progeny. Int J Med Microbiol. 2018;308(7):890-8.

23. Schmidt $H$, Bielaszewska M, Karch H. Transduction of enteric Escherichia coli isolates with a derivative of Shiga toxin 2-encoding bacteriophage phi3538 isolated from Escherichia coli O157:H7. Appl Environ Microbiol. 1999;65(9): 3855-61.

24. Acheson DW, Reidl J, Zhang X, Keusch GT, Mekalanos JJ, Waldor MK. In vivo transduction with Shiga toxin 1-encoding phage. Infect Immun. 1998;66(9):4496-8.
25. Toth I, Schmidt H, Dow M, Malik A, Oswald E, Nagy B. Transduction of porcine enteropathogenic Escherichia coli with a derivative of a Shiga toxin 2-encoding bacteriophage in a porcine ligated ileal loop system. Appl Environ Microbiol. 2003;69(12):7242-7.

26. Gamage SD, Patton AK, Hanson JF, Weiss AA. Diversity and host range of Shiga toxin-encoding phage. Infect Immun. 2004;72(12):7131-9.

27. Iversen H, LA-L TM, Aspholm M, Arnesen LP, Lindback T. Commensal E. coli Stx2 lysogens produce high levels of phages after spontaneous prophage induction. Front Cell Infect Microbiol. 2015;5:5.

28. Gamage SD, Patton AK, Strasser JE, Chalk CL, Weiss AA. Commensal bacteria influence Escherichia coli 0157:H7 persistence and Shiga toxin production in the mouse intestine. Infect Immun. 2006;74(3):1977-83.

29. Su LK, Lu CP, Wang Y, Cao DM, Sun JH, Yan YX. Lysogenic infection of a Shiga toxin 2-converting bacteriophage changes host gene expression, enhances host acid resistance and motility. Mol Biol. 2010;44(1):60-73.

30. Veses-Garcia M, Liu X, Rigden DJ, Kenny JG, McCarthy AJ, Allison HE. Transcriptomic analysis of Shiga-toxigenic bacteriophage carriage reveals a profound regulatory effect on acid resistance in Escherichia coli. Appl Environ Microbiol. 2015;81(23):8118-25.

31. Xu X, McAteer SP, Tree JJ, Shaw DJ, Wolfson EB, Beatson SA, et al. Lysogeny with Shiga toxin 2-encoding bacteriophages represses type III secretion in enterohemorrhagic Escherichia coli. PLoS Pathog. 2012;8(5):e1002672.

32. Hernandez-Doria JD, Sperandio V. Bacteriophage transcription factor Cro regulates virulence gene expression in Enterohemorrhagic Escherichia coli. Cell Host Microbe. 2018;23(5):607-17 e6.

33. Yin S, Rusconi B, Sanjar F, Goswami K, Xiaoli L, Eppinger M, et al. Escherichia coli 0157:H7 strains harbor at least three distinct sequence types of Shiga toxin 2a-converting phages. BMC Genomics. 2015;16:733.

34. Jensen L, Kuhn M, Stark M, Chaffron S, Creevey C, Muller J, et al. STRING 8a global view on proteins and their functional interactions in 630 organisms. Nucleic Acids Res. 2009;37(Database issue):D412-6.

35. Gyaneshwar P, Paliy O, McAuliffe J, Popham DL, Jordan Ml, Kustu S. Sulfur and nitrogen limitation in Escherichia coli K-12: specific homeostatic responses. J Bacteriol. 2005;187(3):1074-90.

36. Keseler IM, Mackie A, Santos-Zavaleta A, Billington R, Bonavides-Martinez C, Caspi R, et al. The EcoCyc database: reflecting new knowledge about Escherichia coli K-12. Nucleic Acids Res. 2017;45(D1):D543-D50.

37. Ptashne M, Jeffrey A, Johnson AD, Maurer R, Meyer BJ, Pabo CO, et al. How the lambda repressor and cro work. Cell. 1980;19(1):1-11.

38. Matsushita K, Ohnishi T, Kaback HR. NADH-ubiquinone oxidoreductases of the Escherichia coli aerobic respiratory chain. Biochemistry. 1987;26(24):7732-7.

39. Sanwal BD. Allosteric controls of amphilbolic pathways in bacteria. Microbiol Mol Biol Rev. 1970;34(1):20-39.

40. Danson MJ, Weitzman PD. Functional groups in the activity and regulation of Escherichia coli citrate synthase. Biochem J. 1973;135(3):513-24.

41. Pruss BM, Nelms JM, Park C, Wolfe AJ. Mutations in NADH:ubiquinone oxidoreductase of Escherichia coli affect growth on mixed amino acids. J Bacteriol. 1994;176(8):2143-50.

42. Berrios-Rivera SJ, Bennett GN, San KY. Metabolic engineering of Escherichia coli: increase of NADH availability by overexpressing an NAD(+)-dependent formate dehydrogenase. Metab Eng. 2002;4(3):217-29.

43. Georgellis D, Kwon O, Lin EC. Amplification of signaling activity of the arc two-component system of Escherichia coli by anaerobic metabolites. An in vitro study with different protein modules. J Biol Chem. 1999; 274(50):35950-4.

44. Rolfe MD, Ter Beek A, Graham Al, Trotter EW, Asif HM, Sanguinetti G, et al. Transcript profiling and inference of Escherichia coli K-12 ArcA activity across the range of physiologically relevant oxygen concentrations. J Biol Chem. 2011;286(12):10147-54

45. Holm AK, Blank LM, Oldiges M, Schmid A, Solem C, Jensen PR, et al. Metabolic and transcriptional response to cofactor perturbations in Escherichia coli. J Biol Chem. 2010;285(23):17498-506.

46. Salmon KA, Hung SP, Steffen NR, Krupp R, Baldi P, Hatfield GW, et al. Global gene expression profiling in Escherichia coli K12: effects of oxygen availability and ArcA. J Biol Chem. 2005;280(15):15084-96.

47. Park DM, Akhtar MS, Ansari AZ, Landick R, Kiley PJ. The bacterial response regulator ArcA uses a diverse binding site architecture to regulate carbon oxidation globally. PLoS Genet. 2013;9(10):e1003839.

48. Conway T, Cohen PS. Commensal and pathogenic Escherichia coli metabolism in the gut. Microbiol Spectr. 2015;3(3). https://doi.org/10.1128/ microbiolspec.MBP-0006-2014. 
49. Fabich AJ, Jones SA, Chowdhury FZ, Cernosek A, Anderson A, Smalley D, et al. Comparison of carbon nutrition for pathogenic and commensal Escherichia coli strains in the mouse intestine. Infect Immun. 2008;76(3):1143-52.

50. Saile N, Voigt A, Kessler S, Stressler T, Klumpp J, Fischer L, et al. Escherichia coli 0157:H7 strain EDL933 harbors multiple functional prophage-associated genes necessary for the utilization of 5-N-Acetyl-9-O-acetyl Neuraminic acid as a growth substrate. Appl Environ Microbiol. 2016;82(19):5940-50.

51. Saile N, Schwarz L, Eissenberger K, Klumpp J, Fricke FW, Schmidt H. Growth advantage of Escherichia coli O104:H4 strains on 5-N-acetyl-9-O-acetyl neuraminic acid as a carbon source is dependent on heterogeneous phage-borne nanS-p esterases. Int J Med Microbiol. 2018;308(4):459-68.

52. Feuerbaum S, Saile N, Pohlentz G, Muthing J, Schmidt H. De-Oacetylation of mucin-derived sialic acids by recombinant NanS-p esterases of Escherichia coli 0157:H7 strain EDL933. Int J Med Microbiol. 2018;308(8):1113-20.

53. Chang DE, Smalley DJ, Tucker DL, Leatham MP, Norris WE, Stevenson SJ, et al. Carbon nutrition of Escherichia coli in the mouse intestine. Proc Natl Acad Sci U S A. 2004;101(19):7427-32.

54. Miranda RL, Conway T, Leatham MP, Chang DE, Norris WE, Allen JH, et al. Glycolytic and gluconeogenic growth of Escherichia coli 0157:H7 (EDL933) and E. coli K-12 (MG1655) in the mouse intestine. Infect Immun. 2004; 72(3):1666-76.

55. Jones SA, Chowdhury FZ, Fabich AJ, Anderson A, Schreiner DM, House AL et al. Respiration of Escherichia coli in the mouse intestine. Infect Immun. 2007;75(10):4891-9.

56. Jones SA, Gibson T, Maltby RC, Chowdhury FZ, Stewart V, Cohen PS, et al. Anaerobic respiration of Escherichia coli in the mouse intestine. Infect Immun. 2011;79(10):4218-26.

57. Allison KR, Brynildsen MP, Collins JJ. Metabolite-enabled eradication of bacterial persisters by aminoglycosides. Nature. 2011;473(7346):216-20

58. Shan Y, Brown Gandt A, Rowe SE, Deisinger JP, Conlon BP, Lewis K. ATPdependent Persister formation in Escherichia coli. MBio. 2017;8(1):e02267-16.

59. Harms A, Maisonneuve E, Gerdes K. Mechanisms of bacterial persistence during stress and antibiotic exposure. Science. 2016;354(6318):aaf4268.

60. Dorr T, Vulic M, Lewis K. Ciprofloxacin causes persister formation by inducing the TisB toxin in Escherichia coli. PLoS Biol. 2010;8(2):e1000317.

61. Yamamoto N, Isshiki R, Kawai Y, Tanaka D, Sekiguchi T, Matsumoto S, et al. Stochastic expression of lactate dehydrogenase a induces Escherichia coli persister formation. J Biosci Bioeng. 2018;126(1):30-7.

62. Bachmann BJ. Derivations and genotypes of some mutant derivatives of Escherichia coli K-12. In: Neidhardt FCCIR, Ingraham JL, Lin ECC, Low Jr KB, Magasanik B, Reznikoff WS, Riley M, Schaechter M, Umbarger HE, editors. Escherichia coli and Salmonella typhimurium cellular and molecular biology. 2nd ed. Washington: ASM Press; 1996. p. 2460-88.

63. Berger $P$, Knödler M, Forstner KU, Berger M, Bertling C, Sharma CM, et al. The primary transcriptome of the Escherichia coli O104:H4 pAA plasmid and novel insights into its virulence gene expression and regulation. Sci Rep. 2016;6:35307.

64. Andrews S. FastQC: a quality control tool for high throughput sequence data. 2010. http://www.bioinformatics.babraham.ac.uk/projects/fastqc/.

65. Martin M. Cutadapt removes adapter sequences from high-throughput sequencing reads. EMBnet.journal. 2011;17(1):3.

66. Hannon GJ. FASTX-Toolkit.2010 http://hannonlab.cshl.edu/fastx_toolkit/.

67. Förstner KU, Vogel J, Sharma CM. READemption-a tool for the computational analysis of deep-sequencing-based transcriptome data. Bioinformatics. 2014;30(23):3421-3.

68. Hoffmann S, Otto C, Kurtz S, Sharma CM, Khaitovich P, Vogel J, et al. Fast mapping of short sequences with mismatches, insertions and deletions using index structures. PLoS Comput Biol. 2009;5(9):e1000502.

69. Love MI, Huber W, Anders S. Moderated estimation of fold change and dispersion for RNA-seq data with DESeq2. Genome Biol. 2014;15(12):550.

70. Gutnick D, Calvo JM, Klopotowski T, Ames BN. Compounds which serve as the sole source of carbon or nitrogen for Salmonella typhimurium LT-2. J Bacteriol. 1969;100(1):215-9.

71. Haarmann N, Berger M, Kouzel IU, Mellmann A, Berger P. Comparative virulence characterization of the Shiga toxin phage-cured Escherichia coli 0104:H4 and enteroaggregative Escherichia coli. Int J Med Microbiol. 2018; 308(7):912-20

72. Johnson M, Zaretskaya I, Raytselis Y, Merezhuk Y, McGinnis S, Madden TL. NCBI BLAST: a better web interface. Nucleic Acids Res. 2008;36(Web Server issue):W5-9.
73. Vaas LA, Sikorski J, Hofner B, Fiebig A, Buddruhs N, Klenk HP, et al. Opm: an R package for analysing OmniLog(R) phenotype microarray data. Bioinformatics. 2013;29(14):1823-4.

74. Wang RF, Kushner SR. Construction of versatile low-copy-number vectors for cloning, sequencing and gene expression in Escherichia coli. Gene. 1991; 100:195-9.

75. R Core Team. R: a language and environment for statistical computing. $R$ Foundation for Statistical Computing, Vienna, Austria. 2017 URL http://www. R-project.org/.

76. Wickham H. ggplot2: Elegant Graphics for Data Analysis. New York: Springer-Verlag; 2009.

77. Edgar R, Domrachev M, Lash AE. Gene expression omnibus: NCBI gene expression and hybridization array data repository. Nucleic Acids Res. 2002; 30(1):207-10.

\section{Publisher's Note}

Springer Nature remains neutral with regard to jurisdictional claims in published maps and institutional affiliations.
Ready to submit your research? Choose BMC and benefit from:

- fast, convenient online submission

- thorough peer review by experienced researchers in your field

- rapid publication on acceptance

- support for research data, including large and complex data types

- gold Open Access which fosters wider collaboration and increased citations

- maximum visibility for your research: over $100 \mathrm{M}$ website views per year

At BMC, research is always in progress.

Learn more biomedcentral.com/submissions 